\title{
Políticas Públicas X Educação: \\ A Perfeita Junção para a recuperação dos Jovens Internos em processo de Realibitação na Cidade de Juazeiro do Norte-CE
}

\author{
Julyanne Noêmia Ribeiro Duarte Romão ${ }^{1}$; Fabiana Correia Bezerra²
}

\begin{abstract}
Resumo: Buscar melhoria para uma sociedade desorganizada e despreparada é preciso que a educação e as políticas públicas estejam interligadas e em plena harmonia para que se tenham bons resultados. Falar em reabilitação de uma juventude quase que praticamente perdida, chega a ser uma utopia. Dentro deste contexto, o intuito deste artigo é buscar parcerias com as políticas públicas e os profissionais da educação para que haja a oportunidade de mudança e eficácia nessa busca de reabilitação. Junto com uma equipe multifuncional, recuperar não somente os internos, mas também, a família que junto com ele, encontra-se doente e necessita de ajuda. A sociedade moderna é uma corporação de disposições que fundamentalmente se encontram as oportunidades de realização profissional e de sobrevivência, aplicando-se o que se sabe e ainda acrescenta outros saberes, assim como trocando trabalho por dinheiro. Para que haja uma recuperação verdadeiramente efetiva, vale ressaltar a aplicação de terapia em grupo roda de conversa, cursos profissionalizantes, assistência psicológica e conhecimento com relação ao estado que se encontram. No entanto, a reabilitação psicossocial e a reinserção social são analisadas, pelos documentos normativos que satisfazem as políticas públicas sobre drogas, como linhas centrais no cuidado aos indivíduos com dificuldades relacionadas ao uso de substâncias psicoativas. Como metodologia será aplicada o método de cunho qualitativo, pesquisas bibliográficas e pesquisa-ação. E por fim, a busca de parcerias com as políticas públicas e empresas para que haja uma ressocialização do indivíduo, e assim, o mesmo sinta-se um cidadão recuperado com uma profissão que o volte a dignidade social.
\end{abstract}

Palavras - chave: Reabilitação, Equipe Multifuncional, Família, Dignidade Social.

\section{Public Policies X Education: \\ The Perfect Junction for the Recovery Of Internal Young People in the process of Rehabilitation in the City of Juazeiro do Norte-CE}

\begin{abstract}
To seek improvement for a disorganized and unprepared society requires education and public policies to be intertwined and in full harmony for good results. To talk about the rehabilitation of a youth almost lost, it becomes a utopia. Within this context, the purpose of this article is to seek partnerships with public policies and education professionals so that there is an opportunity for change and effectiveness in this search for rehabilitation. Along with a multifunctional team, recover not only the inmates, but also the family that together with him, is sick and needs help. Modern society is a corporation of dispositions that fundamentally find the opportunities of professional fulfillment and survival, applying what is known and still adds other knowledge, as well as exchanging work for money. For a truly effective recovery, it is worth emphasizing the application of group therapy talk wheel, professional courses, psychological assistance and knowledge regarding the state they are. However, psychosocial rehabilitation and social reintegration are analyzed by normative documents that satisfy
\end{abstract}

\footnotetext{
${ }^{1}$ Julyanne Noêmia Ribeiro Duarte Romão - Graduada em Psicologia pela \UNILEÃO - Universidade Leão Sampaio . Email: julyanneduarte_psi@hotmail.com;

${ }^{2}$ Fabiana Correia Bezerra - Mestre em Desenvolvimento Regional Sustentável pela UFCA- Universidade Federal do Cariri Graduada em Administração pela UVA- Universidade Vale do Acarau . E-mail: fabianacbezerra@gmail.com.
} 
public drug policies as central guidelines in the care of individuals with difficulties related to the use of psychoactive substances. As methodology will be applied the qualitative method, bibliographical research and research-action. And finally, the search for partnerships with public policies and companies so that there is a resocialization of the individual, and thus, the same feel a recovered citizen with a profession that brings him back to social dignity.

Keywords: Rehabilitation, Multifunctional Team, Family, Social Dignity.

\section{Introdução}

Na perspectiva de colaborar com a organização e qualificação dos serviços de proteção social especial, propõe-se ofertar um apoio psicossocial de cunho multidisciplinar, englobando vários profissionais da saúde e da educação, para que haja de forma efetiva um indivíduo verdadeiramente recuperado, junto com a sua família cujo tem o papel principal para essa recuperação. É importante salientar que não é apenas o indivíduo que dependente de drogas lícitas e ilícitas que precisam de ajuda; existe também a família que precisa de suporte para ajudá-lo neste desafio.

$\mathrm{O}$ enfoque de nossa pesquisa foi direcionado no contexto de uma comunidade terapêutica que trabalha em sistema de internamento, sob abstinência total. Porém ainda existem falhas no que se refere a equipe multifuncional que ainda se corrompe e deixa falhas, impedindo assim uma recuperação justa e efetiva.

Para que haja essa conquista é importante uma dedicação mútua, capacitação freqüente com os colaboradores, compreensão da família e dedicação na atuação dos indivíduos que atuam diretamente com os dependentes. Palavras grosseiras causam revoltas e leva o tratamento à estaca zero.

\section{Referencial Teórico}

A dependência química e do álcool atravessa praticamente todas as ações na totalidade da assistência social, seja na probabilidade preventiva ou de tratamento. E vai se contrapondo desde o trabalho com crianças e adolescentes, até o trabalho com a terceira idade, mulheres vitimizadas, moradores de bairros mais afastados e menos favorecidos ou assentamentos, depara-se com a problemática das drogas e do álcool, de configuração direta ou indireta. 
Para Saraceno (2016), a reabilitação se compõe na abertura das possibilidades de comercialização e aumento do poder contratual dos sujeitos em três linhas fundamentais: a casa, a rede social e o trabalho. O primeiro deles, a casa, está relacionado a uma propriedade do espaço onde se vive e sua relação com a organização do ambiente e artefatos, bem como a afabilidade com os outros (Saraceno, 2001).

A dependência química abarca o uso de todos os tipos de substâncias psicoativas; ou seja, qualquer droga que desvia o desempenho e que possa causar atrelamento: álcool, maconha, cocaína, crack, dentre outras.

A Organização Mundial de Saúde considera a dependência química como doença, porque há alteração da composição e no comportamento normal da pessoa, sendo-lhe maléfico. Ainda para ciência não existe motivo específico, mas é fruto de uma série de fatores que atuam ao mesmo tempo no emocional, onde uns são mais dominantes em algumas pessoas peculiares, do que em outras. E assim, alcança o ser humano em três dimensões básicas (biológica, psíquica e espiritual), reconhecida como uma questão social, em todas as classes sociais.

Sanches (2018) afirma que a dependência química piora cada vez mais com o passar do tempo, leva a pessoa a um aniquilamento lento de si mesmo, apreendendo sua vida pessoal, familiar, profissional e social.

De acordo com essa situação, muitas são as instituições junto à sociedade civil que têm se proposto a desenvolver um trabalho de assistência e tratamento a dependentes químicos: grupos anônimos, clínicas ou casas de recuperação, hospitais, etc. O número delas cresce à medida que a demanda aumenta, levando grupos, comunidades, associações, clubes de serviços e igrejas a organizarem trabalhos de atendimento a esse segmento.

As propostas de formas de atendimento a essa população específica variam de acordo com a visão de mundo e perspectiva política, ideológica e religiosa dos diferentes grupos. No entanto, ainda há muito a se trabalhar para que haja verdadeiramente uma reabilitação contínua. Pois na região do cariri cearense ainda deixa muito a desejar.

\section{O uso e a dependência química dos jovens}

Debater assuntos ligados aos conceitos, à compreensão e à elaboração de modos de encarar a dependência química, de acordo com Ornellas, (1999, p. 20) ao longo do contexto histórico, coloca em evidência a demanda da evolução histórica da favorável prática médica 
como instituição que detém a legitimidade hegemônica do domínio desse cuidado e dos saberes relativos à doença e à saúde. Portanto, seguindo os trâmites da história, é necessário começar a falar sobre saúde e doença refletindo conhecimentos que foram produzidos na Antiguidade. Sevalho (1993), afirma que as primeiras representações de saúde e doença estavam ligadas a uma questão mágica, como no caso das concepções dos antigos povos da Mesopotâmia, uma vez que para eles as doenças eram atentadas por controles de institutos sobrenaturais, com as quais o ser humano não podia competir. A partir dessa conclusão, os sujeitos eram conscientizados, geralmente que necessitam de ajuda para vencer a dependência, bem como explicitaram o desejo de se submeterem ao tratamento.

Frequentemente estão com suas relações sócio-familiares prejudicadas, quando não aniquiladas, e com seus planos educativos e profissionais descontinuados. Onde na verdade estão vivenciando um processo de exclusão social decorrente do consumo de álcool ou de outras drogas de forma reincidente e dependente. Esse processo de exclusão já é instaurado antes da dependência química, pois na maioria das vezes, essas instituições recebem em seus quadros, pessoas oriundas de segmentos sociais já excluídos social e economicamente que, conforme reportagem da Folha de São Paulo, de 26/09/98, no Brasil integram 63\% da população.

Em conseqüência, a conclusão do tratamento, o que geralmente dura de 8 a 10 meses, o sujeito recuperado se vê diante de outro desafio: o retorno ao meio sócio-familiar. Trata-se do reencontro das relações no âmbito da família, do trabalho, da escola, onde vem cheio de receios e que é decisivo para o seu retorno ou não ao uso de drogas. Dependerá de como essa reinserção é trabalhada, enfrentada e assumida por todos os envolvidos nesse processo: profissionais, egressos e familiares.

\section{A Reabilitação Psicossocial e a contribuição das Políticas Públicas x Educação}

A utilização do álcool e outras drogas se compõem como um problema de saúde pública, problemas esses, decorrentes como afirma Machado (2006), se estendem ao usuário, à família e aos acidentes de trânsito, e relacionam o tráfico com o crime e a violência. De acordo com Carlini(2006), estima-se que mais de 20 milhões de brasileiros fazem ou fizeram uso de drogas na vida Segundo o Relatório Mundial sobre Drogas, cerca de 29 milhões de pessoas em todo o mundo sofrem de transtornos por uso de substâncias (United Nations, 2016). 
Tendo em vista o aumento da demanda no que se refere à questão das drogas, nas últimas décadas houve a formulação diversas políticas, leis e portarias a fim de subsidiar o cuidado aos usuários de drogas em termos de prevenção e tratamento. As políticas de atenção aos usuários de álcool e outras drogas estão atravessadas pelas Políticas de Saúde Mental que se desenvolveram no contexto da Reforma Psiquiátrica.

Inúmeras metodologias utilizadas para atuação com os pacientes psiquiátricos no processo de fechar gradativamente hospitais psiquiatricos foram transpostos para lidar também com os usuários de drogas sem levar em conta todo o processo político-econômico no qual se insere o uso de substâncias psicoativas. Isso fica evidente ao se retomar as políticas e portarias direcionadas ao uso de drogas, para verificar como a reabilitação psicossocial, a reinserção social e ainda a inclusão social são apresentadas nesses documentos. Inicialmente, a Portaria $\mathrm{n}^{\circ}$ 336, de 2002, estabelece as diretrizes de funcionamento para os Centros de Atenção Psicossocial (CAPS) em suas diversas modalidades, entre elas o CAPSad. Entre as atividades desse serviço, além dos atendimentos individuais e grupais, oficinas terapêuticas e visitas domiciliares, ressaltam-se as "atividades comunitárias enfocando a integração do dependente químico na comunidade e sua inserção familiar e social" (Brasil, 2002a).

Vale salientar que, nessa Portaria, não houve menção alguma aos termos reinserção social, reabilitação psicossocial ou inclusão social, mas são previstas ações de assistência comunitária junto ao paciente, porém sem indicações de como tais atividades devem ser conduzidas.

\section{A Criação da Portaria ${ }^{\circ} 816$}

No ano de 2002, por meio da Portaria $n^{\circ}$ 816, o Ministério da Saúde instituiu o Programa Nacional de Atenção Comunitária Integrada a Usuários de Álcool e Outras Drogas, que considera a necessidade de estruturar e fortalecer uma rede de atenção comunitária, articulada às redes de saúde e social, com ênfase na reabilitação e reinserção social dos usuários.

Nessa Portaria, a reinserção, a reabilitação e a inclusão social não são mencionadas enquanto finalidades do Programa. Todavia, nos objetivos do Programa, há a organização e implementação de uma rede de serviços extra-hospitalares, articulada à rede de atenção psicossocial, preconizando-se, também, a realização de atividades comunitárias (Brasil, 2002b). 
Nesse sentido, apesar da não utilização dos termos pesquisados, essa Portaria menciona os serviços substitutivos sugeridos pela Reforma Psiquiátrica e as atividades que visam o retorno do sujeito para as atividades sociais na comunidade.

Posteriormente, em 2003, criou-se a Política do Ministério da Saúde para Atenção Integral a Usuários de álcool e outras Drogas, na qual salienta-se a necessidade de estruturar, organizar e fortalecer a rede de serviços disponíveis de modo a atender aos usuários de forma integrada e com ênfase na reabilitação e reinserção social dos usuários de drogas.

\section{O uso do crack e as conseqüências devastadoras para toda família}

De acordo com Souza, (2010) o crack tem origem da America do Norte e aos poucos foi ocupando o espaço da cocaína por ser um produto mais barato e de fácil acesso, causando desde o primeiro contato uma dependência contínua.

A droga é composta por uma pasta de cocaína, cal, cimento, querosene, ácido sulfúrico, acetona, amônia e soda caustica, vista em sua composição pura. Porém, atualmente outros ingredientes foram adicionados como por exemplo bicarbonato, talco, vidro, fezes de animais entre outros.

O desencadeamento da dependência, está associado também ao efeito de prazer momentâneo, alterando comportamento do indivíduo, indo além das suas possibilidades, pondo em risco toda a família. Para Carlini (2001), a pressão, de acordo com o sistema cardiovascular pode se elevar e o coração pode bater muito mais rápido e, em casos extremos, chegar a produzir uma parada cardíaca. O usuário, neste caso, poderá chegar a óbito.

\section{Políticas Públicas x Educação}

O Estado dentro dos seus direitos e deveres na nossa constituição tem a responsabilidade de promover políticas públicas para o bem-estar da sociedade em atendimento a recuperação dos indivíduos dependentes de drogas e a reestruturação da família.

Neste sentido, a Política e a Educação precisam estar interligadas, como afirma Arroyo (2014) como as gêmeas siamesas, uma colada na outra e totalmente dependente de toda e qualquer ação que seja feita em favor de todos. Para que haja verdadeiramente a recuperação 
de um indivíduo dependente de drogas, além do internamento, é preciso que esses sujeitos, ante de voltar a convivência social, ele precisa ser moldado, educado para ser inserido nesse meio. É importante salientar que exista oportunidades e possibilidades.

Os centros de reabilitação precisam estar preparados para recepcionar esse sujeito que possui em seu passado histórias doloridas que precisam ser superadas. Neste momento, entra a contribuição das políticas públicas, onde buscam parcerias e metodologias adequadas para que valha a pena essa luta e a recuperação das famílias.

Como por exemplo levar para dentro desses centros de recuperação oficinas de artes, artesanato, educação, leitura, rodas de conversas, terapia não só para o dependente, mas também para a família, os colaboradores e, somente assim, haverá uma recuperação verdadeiramente sustentável.

\section{Processos Metodológicos}

A presente pesquisa trata-se de uma revisão bibliográfica, onde Gil (2010) afirma que este tipo de pesquisa é elaborado com base no material já publicado. No entanto, como fontes de pesquisa foram utilizadas artigos, livros, jornais e revistas científicas referenciadas ao uso, dependência e a necessidade de tratamentos de adolescentes dependentes principalmente do crack, vistos pela sociedade como irrecuperáveis. Onde os mesmos são vítimas de uma sociedade que pouco se importa com o grupo excluído.

Nessa Política, ressalta-se que o CAPSad, por meio das estratégias de RD, deve oferecer assistência a usuários de álcool e outras drogas e, dentre outras ações, deve promover a reinserção social dos usuários, recorrendo para isso a um trabalho intersetorial, juntamente com a educação, lazer, esporte e cultura, de modo a atender ao sujeito de maneira conjunta (Brasil, 2004).

\section{Considerações Finais}

A partir da reflexão acima apresentada, é possível finalizar que debater a dependência química na atualidade é tratar a questão do processo saúde/doença, tanto em termos bem- 
conceituados, de formação e de atuação dos profissionais multidisciplinares na área de saúde, quanto no que se refere à questão do tratamento e da promoção da educação.

Entretanto, a partir do século XX, são constatadas transformações no que diz respeito ao processo saúde/doença, sendo que o uso de substâncias psicoativas assumiu dimensões alarmantes, tornando-se um complexo problema em termos de saúde pública, o qual exige a definição de intervenções particulares. Porém, falar do uso de drogas não é falar apenas de uma questão biológica, é falar de um indivíduo integral, para o qual as drogas possuem uma representação específica.

Portanto, o tratamento da dependência química na atualidade, bem como as intervenções visando a promoção da saúde e a prevenção do uso de drogas, devem romper com o modelo cartesiano, apesar das dificuldades ainda vivenciadas, e assumir que reduzir o fenômeno da droga em nossa realidade é algo que depende da interação entre vários grupos, exigindo mudanças substanciais na organização social, diminuindo drasticamente as desigualdades presentes nesse contexto e nesse tratamento, er a responsabilidade de inserir a família.

Também são necessárias mudanças na formação dos profissionais que lidam com essa questão, além de alterações na forma de encarar o paciente ou o indivíduo que apresenta maior vulnerabilidade em relação à droga, encarando os mesmos como seres ativos, que possuem saberes e fazeres próprios, diretamente implicados no processo saúde/doença.

Por fim, é de suma importância, no momento da internação, ocupar o tempo do indivíduo com leituras, trabalhos artesanais, músicas entre outras atividades. Somente assim, ele sairá preparado para enfrentar a sociedade que o condenava e não mais confia nas sua ações. E especialmente a família necessita também, ser trabalhada.

\section{Referências}

ARROYO, Miguel G. Outros Sujeitos, Outras Pedagogias/ Miguel G. Arroyo. 2 ed.Petrópolis, RJ: Vozes, 2014.

ORNELLAS, C. (1999). As doenças e os doentes: a apreensão das práticas médicas no modo de produção capitalista. Revista LatinoAmericana de Enfermagem, 7, 19-26

SARACENO, B. Libertando identidades: Da reabilitação psicossocial à cidadania possível (2a. ed.). Rio de Janeiro, RJ: Te Corá Editora. (2001). 
Reabilitação Psicossocial: Uma estratégia para a passagem do milênio. In A. Pitta (org.), Reabilitação Psicossocial no Brasil (pp. 19-26). São Paulo, SP: Hucitec. (2016)

SANCHES, Laís Ramos. Reabilitação Psicossocial e Reinserção Social de pessoas com problemas decorrentes do uso de drogas na perspectiva de profissionais do CAPSad /Laís Ramos Sanches; orientador Marcelo Dalla Vecchia. São João Del-Rei, 69p. 2018.

SEVALHO, G. Uma abordagem histórica das representações sociais de saúde e doença. Cadernos de Saúde Pública, 1993, 9, 349- 363.

\section{Como citar este artigo (Formato ABNT):}

ROMÃO, Julyanne Noêmia Ribeiro Duarte; BEZERRA, Fabiana Correia. Políticas Públicas X Educação: A Perfeita Junção para a recuperação dos Jovens Internos em processo de Realibitação na Cidade de Juazeiro do Norte-CE. Id on Line Rev.Mult. Psic., Fevereiro/2020, vol.14, n.49, p. 759767. ISSN: 1981-1179.

Recebido: 05/10/2019;

Aceito: 07/11/2019. 